\title{
Germanica
}

\section{Einiges über Grenz-Verrückungen}

Eindrücke beim Lesen von Elfriede Czurdas Texten «Diotima oder die Differenz des Glücks» und «Signora Julia»

\section{Erika Tunner}

\section{OpenEdition}

\section{Journals}

Édition électronique

URL : http://journals.openedition.org/germanica/2501

DOI : 10.4000/germanica. 2501

ISSN : 2107-0784

Éditeur

Université de Lille

\section{Édition imprimée}

Date de publication : 30 juin 1990

Pagination : 109-114

ISSN : 0984-2632

\section{Référence électronique}

Erika Tunner, «Einiges über Grenz-Verrückungen », Germanica [Online], 7| 1990, Online erschienen am: 22 Mai 2014, abgerufen am 06 Oktober 2020. URL : http://journals.openedition.org/germanica/2501 ; DOI : https://doi.org/10.4000/germanica.2501

Ce document a été généré automatiquement le 6 octobre 2020.

(c) Tous droits réservés 


\title{
Einiges über Grenz-Verrückungen
}

\author{
Eindrücke beim Lesen von Elfriede Czurdas Texten «Diotima oder die \\ Differenz des Glücks» und «Signora Julia»
}

\section{Erika Tunner}

1 In dem Prosatext Signora Julia wird in indirekter Rede aus einem Brief Julias an den fernen Geliebten Arkadius berichtet:

Das Leben vagabundiere, sei hier und da, nur die Veränderung sei Leben, der stete Wandel. Arkadius habe das schneller begriffen als sie. Unter einem Vorwand habe er sich auf den Weg gemacht: einen Weg, der ohne bestimmte Richtung weiterführe ${ }^{1}$.

2 Was hier über das Leben gesagt wird, scheint auch auf das Werk von Elfriede Czurda zuzutreffen. Wohl gibt es Grenzen, Abgrenzungen, Grenzlinien, Marksteine des Anhaltens, doch sie werden verrückt, sind seltsam mobil, das Konstruktionsgerüst der Personen und des Geschehens wird verschoben, es vagabundiert. So sind die Schlüsse auch keine Abschlüsse, sondern eher das vorläufige Ende einer Geschichte, die in einer anderen Richtung oder ohne bestimmte Richtung weiterführen kann, entwegt und unentwegt.

Die beiden Erzählungen Elf riede Czurdas, Diotima oder die Differenz des Glücks und Signora Julia erproben Abschiedssituationen, also Grenzsituationen. Die Sprache bewegt sich in Zitaten, Sprichwörtern, Metaphern und Assoziationen, in sogenannten «stehenden» Redewendungen, welche aber, kaum daß sie stehen, sich fortwährend wenden, ihr Stehen in Gang bringen, in einen seltsam wirbelnden Gang. In dem Roman Kerner galoppieren sie nur so dahin, ohne Rücksicht auf die Laufgeschwindigkeit des Lesers. Hopplahopp springt es da über die Hürden, über die Grenzen, in ein offenes Gelände, wo aus den geordneten Verhältnissen die chaotische Kehrseite geradezu vulkanisch herausgeschleudert wird. Jedenfalls scheint es einem so, wenn man sich dem Sog dieser Prosa überläßt, gewissermaßen wie ein Schiffer im Kahne die Ruder einlegt und die Strömung hinabtreibt.

Daß Diotima oder die Differenz des Glücks an die Diotima Hölderlins denken läßt, daß in Signora Julia die beiden Hauptgestalten Julia und Arkadius an Julia und Romeo sowie an die arkadische Wunschlandschaft erinnenn, ist unvermeidlich. Doch handelt es sich 
keineswegs um Modelle, sondern eher um «Fälschungen» der Modelle. Die gewohnte Thematik wird aufgelöst, neue Verbindungen setzen sich zusammen, aus einem zunächst scheinbar impressionistischen Tongemenge kristallisieren sich einzelne polytonale Bezirke heraus. Bezeichnenderweise wird in Diotima oder die Differenz des Glücks immer wieder auf Alexander Scriabin aufmerksam gemacht, an dessen Kompositionstechnik Elf riede Czurdas Schreibweise den Leser manchmal denken läßt. In Scriabins Sinfonie Poème de Vextase erfolgt aus Sehnsucht (erster Teil) Schmerz (das Lento des Mittelteils) und daraus die Steigerung zur höchsten Extase. Diese Aufeinanderfolge, wenn auch nicht in derselben Reihenfolge, bestimmt auch die einzelnen Sequenzen in Diotima oder die Differenz des Glücks un in Signora Julia. Sehnsucht und Extase streben ins Grenzenlose, in eine utopische Glückseligkeit, denn beide verlangen nach dem Nicht-Leistbaren: Extase nach Dauer, Sehnsucht nach Erfüllung; doch Dauer ist die Vernichtung der Extase, und das Ende der Sehnsucht ist der Tod. Auch Elf riede Czurdas Texte treiben auf solche Höhepunkte zu, brechen dann aber kurz vorher ab, « la chute » heißt es oft genug, und schlagen eine andere Richtung ein. Für den Leser setzt sich dabei ein Netz von Assoziationen zusammen, das sich freilich alsogleich wieder zersetzt: Abélard und Heloïse, Romeo und Julia - dann kein «und» mehr, dann nur: Julia, Diotima. Schon für die Titel ihrer Geschichten hat Elfriede Czurda ja nicht die Namen zweier Figuren gewählt, sondern allein die der Frauen, der Frauen, die sonst immer an zweiter Stelle genannt werden: wer sagt schon Julia und Romeo oder Isolde und Tristan, keinem fiele es ein, plötzlich von «Gretel und Hansel» zu reden oder gar von «Eva und Adam» - vom Schöpfungsmythos der Zweitgeburt gehen wohl überhaupt alle nachfolgenden Zusammenstellungen aus. Gibt es Ausnahmen? Hero und Leander. Und wenn die Umstellung nur im Sprachrhythmus ihre Gründe hätte? Diotima. Julia. Namen von weiblichen Grenzgestalten gesellen sich hinzu, die nur in und durch Grenzüberschreitungen existieren, im Geistigen wie im Elementaren: Sappho. Penthesilea. Undine. All diese Reiminszensen spuken durch den Kopf des Lesers, anund aufgeregt von der Lektüre von Elfriede Czurdas Geschichten.

Daß kein Mythos neu belebt, daß eher das Gefälschte (Verfälschte?) am Mythos bewußt gemacht werden soll, meint der Leser zu verstehen. Es scheint darum zu geben, eine Konstruktion aufzudecken, die nicht mehr - freilich auch nicht weniger... als eine Konstruktion ist. Dieser Eindruck entsteht, wenn man an einer Stelle hängen bleibt, wo in Diotima oder die Differenz des Glücks eine der bekanntesten Geschichten von Herrn Keuner eingeschoben wird:

Was tun Sie, wurde Herr K. gefragt, wenn Sie einen Menschen lieben? Ich mache einen Entwurf von ihm, sagte Herr K., und sorge, daß er ihm änlich wird ${ }^{2}$.

Und danach beginnt man, in der von Herrn K. angebotenen Perspektive zu lesen: entwirft Elfriede Czurda nicht auch ihre Personen und sorgt dann dafür, daß sie dem Entwurf ähnlich werden? Entwerfen ihre Personen nicht wiederum Personen (oft genug auch ihre eigene Person) und suchen dann, den Entwurf festzuhalten oder sagen wir: den Entwurf nicht schwinden zu lassen? Betreten diese Figuren dann nicht den schmalen Grenzpfad zwischen nur erdachter und gestalteter Figur, was sowohl ihre Originalität wie auch ihre Fragilität ausmacht und sie überzeugender erscheinen läßt in den reflexiven Passagen als in den sinnlichen, erotischen oder sexuellen Szenen, wo sie seltsam abstrakt bleiben? Es ist nicht eben leicht, eine Konstruktion mit jenem Körper $\mathrm{zu}$ versehen, dem man die Lust glaubt. Je eindringlicher die Sprache wird, desto angestrengter wirkt die Situation: 
Ich schmecke deine Haut, Julia. Du überfällst mich mit deiner Abwesenheit ganz unwillkürlich. Deine Überfälle sind rücksichtslos [...]. Ich schmecke deine Haut die Schenkel abwärts und seitlich an der Venuswildnis vorbei. Ich spüre, wie mein Leben sich regt bei diesen Gedanken. Die Regung wird zur Erregung, und diese kippt um zur Angst um dein Verschwinden ${ }^{3}$.

7 Auch der Leser läuft Gefahr, seine Erregung des Lesens in die Angst um das Verschwinden der Personen umkippen $\mathrm{zu}$ sehen, weil sie von der Konstruktion aufgesogen werden, sich in der Konstruktion auflösen, weil sie - eben als Konstruktionen - zerebral bleiben und nicht identisch werden mit einer unzerebralen Sprechweise. Dem Leser kommen sie abhanden.

8 «Wie sollte ich meine Verzweiflung bewältigen können, wie sollte ich an Tagen wie dem heutigen die Kraft mobilisieren, auch morgen noch leben zu wollen, wenn ich nicht meine Konstruktion einer Beziehung zu dir hätte. - Verstehst du nun, warum ich alles daran setze, sie aufrechtzuerhalten, diese Konstruktion, und verstehst du auch, welche Katastrophe das Zusammenbrechen dieser Konstruktion für mich bedeutet, mein Wille zur Unsicherheit braucht einen Halt, und diesen Halt verschafft mir die Konstruktion einer glücklichen Situation, und eine glückliche Situation läßt sich nur konstruieren, wenn ich jemanden liebe, sehr liebe... heute, gerade heute brauche ich das Streicheln deiner Hände, damit ich Gestalt annehme - ich bin heute so dünn, ein Strich, der nicht einmal einen Schatten wirft, zu mager dazu, ein Haarstrich [...]. Wenn du mich heute nicht streichelst, gerate ich an einen unumkehrbaren Punkt: Ich verblasse zur Unsichtbarkeit, unfähig, aus eigener Kraft wieder zu Kraft zu kommen ${ }^{4}$.

9 So endet das erste Kapitel von Diotima oder die Differenz des Glücks. Später heißt es dann: «Wohin bin ich verkommen, wozu bin ich verkommen, daß du mich nicht mehr siehst?» ${ }^{5}$. Oder in Signora Julia:

Daß mich deine Existenz anzieht, verwundert mich nicht; daß ich von dir emotionell abhängig bin, erschüttert mich: daß meine Grenzen zerfließen, gut; aber daß es an meinen Kern geht? ${ }^{6}$.

Daß du mich nicht mehr siehst... Daß meine Grenzen zerfließen... ja, daß es an meinen Kern geht... Aber wann sieht man mich nicht, wann zerfließen meine Grenzen, ja wann geht es an meinen Kern? wenn ich (nur noch) zur Konstruktion werde:

Deine Reaktion hat mich erfrischt, weil mich alles erfreut, was von dir kommt (solange du nur meine Konstruktion bist) ${ }^{7}$.

11 So wie die Autorin Macht hat über die konstruierte Figur und entscheidet, was dieser konstruierten Figur zustößt, so konstruiert die konstruierte Figur wiederum ein Du, über das sie Macht hat, und das gleichzeitig ihrer eigenen Konstruktion mehr Konsistenz verleiht. Den konstruierten Figuren wird das Wissen in den Mund gelegt, daß auch Glück nur fortdauernde Konstruktion ist, daß in dieser Konstruktion keine Erwartungen an den andern gestellt und deshalb alle Erwartungen erfüllt werden. Doch wird auch darauf hingewiesen, daß Konstruktionen porös werden und dann ständig vom Einbruch - oder auch nur Einsickern - der Wirklichkeit bedroht sind. Sobald die Grenze überschritten wird zwischen Konstruktion und Wirklichkeit, scheitert die Konstruktion, und mit der Auflösung der Konstruktion zeigt sich die Hinfälligkeit des Mythos.

12 Eine «story» im üblichen Sinne gibt es bei Elfriede Czurda nicht. Es wird kein epischer Raum konstituiert, auch kein chronologisches Nacheinander. Und doch sind Raum und Zeit da, wir brauchen keine story, um zu wissen, was Raum ist, was Zeit wirkt, ob ein 
Leben geglückt oder vertan ist. Es werden Szenen evoziert, Gespräche und Selbstgespräche mitgeteilt, Briefe geschrieben. Kein lineares, kontinuierliches Erzählen, sondern eher ein Denkströmen, eine Art Pendelbewegung zwischen Intellektualität und écriture automatique, die an Verfahrensweisen der Surrealisten denken läßt. Aus Teilen vorausgegangener Gedankenkomplexe werden neue Zusammenhänge gebildet, diese können wiederum aufgespalten werden, sich selbständig machen, im weiteren Verlauf des Textes leitmotivisch erneut auftauchen. Die Sprache verrückt Grenzen, im Verrücken rückt sie zurecht, zeigt in sehr kalkuliert spielerischer Weise den Schein des Seins. Da, wo es um Grenz-Verrückungen geht, ist es nicht eben gemütlich, Behaglichkeit kommt nicht auf. In dem satirisch als Abenteuerroman bezeichneten Text Kerner wird die Entblößungsfunktion der Sprache mit Virtuosität auf die Spitze getrieben, denn indem die Sprache, scheinbar harmlos, ablenkt, lenkt sie erbarmungslos auf die Lüge hin, die sich im Ach-so-Harmlosen verbirgt.

\section{NOTES}

1. - Signora Julia, Rowohlt, 1985, S. 102 f.

2. - Diotima oder die Differenz des Glücks, Rowohlt, 1982, S. 58.

3. - Signora Julia, S. 124.

4. - Diotima oder die Differenz des Glücks, S. 39.

5. - Ebda., S. 49.

6. - Signora Julia, S. 73.

7. - Vgl. dazu auch S. 30, Diotima oder die Differenz des Glücks. 